\title{
LA ESTRUCTURA ANTINÓMICA EN LA ETICA DE NICOLAI HARTMANN
}

\section{La antinomia como problema ético}

Cuando dos proposiciones aparentemente verdaderas se contradicen entre sí, hablamos, en general, de una "antinomia". El término se ha hecho corriente en el lenguaje filosófico desde que Kant lo empleara para indicar los desacuerdos que se producen entre las afirmaciones de la cosmología racional. También puede tratarse de la contradicción en que una proposición, o una ley, puede incurrir consigo misma. En todo caso, se suele decir que la antinomia es una contradicción necesaria, a diferencia de las "paradojas", que son contradicciones aparentes. Desde toda esta perspectiva, la noción de antinomia interesa, en especial -y casi con exclusividad-, a la lógica y a la gnoseología. Su uso en otras disciplinas puede servir para señalar, por ejemplo, la incoherencia de una hipótesis, o. la presencia de alguna falacia en una determinada argumentación que se trata de refutar. El término "antinomia" alude así, en definitiva, a relaciones lógicas.

Pero hay otra manera posible de considerar la antinomia. Consiste en observar su función en el ámbito de la praxis, entendida fundamentalmente como acción moral. Las relaciones antinómicas trascienden aquí la problemática lógica: no las miramos ya como una cuestión inherente a la validez de un argumento, sino ante todo como dificultades que se ofrecen a la conducta concreta. No se trata ya de una oposición o incompatibilidad entre meras "proposiciones", sino, por ejemplo, entre "deberes". Desde luego, es posible siempre una consideración lógica de los imperativos: la llamada "lógica deóntica" desempeña en estos casos un papel aclaratorio que de ningún modo es lícito rechazar. Pero es también necesario advertir que lo antinómico cobra ahora, por así decir, sustancia propia: aunque sigue tratándose de una "relación", ésta tiene aquí, en sí misma, un peso y un significado independientes de los que corresponden a los términos relacionados.

Quizá estuvo entrevisto desde siempre; pero sólo la ética contemporánea ha comprendido cabalmente que el verdadero problema moral no se halla en la oposición entre el bien y el mal, sino en las oposiciones -antinómicas- entre bien y bien, y entre mal y mal. Cuando surge un "impulso" o una "tendencia" que se opone a una determinada norma moral, la consecuencia es un choque que más concierne a la psicología que a la ética. Ésta puede, a lo sumo, intentar una fundamentación de la validez de la norma. En cambio, si la incompatibilidad se presenta entre dos normas, serán también incompatibles los "deberes" a que ellas aluden, y estaremos 
entonces frente a un conflicto moral, y es aquí donde la ética tiene que habérselas con cuestiones que entrañan gran dificultad. Porque, si en el plano gnoseológico - pensemos de nuevo en la dialéctica trascendental kantiana - se "explican" las antinomias mostrando, por ejemplo, que ellas proceden de la aplicación de la razón "más allá de los límites de la experiencia", en el plano ético, en cambio, no existe la posibilidad de "explicaciones" de ese tipo: aquí las antinomias se presentan como circunstancias de la vida concreta, como conflictos cuya significación, cuya trascendencia, es independiente de las causas que los suscitan. Son antinomias que exigen del sujeto moral una toma de posición frente a ellas, antinomias que no pueden eludirse, y por ello nada se adelanta buscándoles una "explicación" en el sentido antes apuntado. Es decir, la explicación de sus causas podría servir, quizá, al sujeto moral, para evitar futuras situaciones conflictuales semejantes. Pero esto tiene aquí una doble relatividad: por un lado, las antinomias que se presentan en la vida práctica poseen en cada caso características muy peculiares, que hacen discutibles las posibles semejanzas que se quieran establecer entre unas y otras, y especialmente con respecto a las causas que las suscitan; y, en segundo lugar, hay que preguntarse hasta qué punto el sujeto moral personal e individual puede, en efecto, evitar las situaciones conflictuales antinómicas, aun en el caso de conocer verdaderamente las causas que las originan. "Explicar" las antinomias morales no es, entonces, totalmente imposible; pero es siempre insuficiente. La ética puede también preguntarse por la posibilidad de "solucionar" antinomias morales. En este problema encuentra, efectivamente, un ámbito más adecuado. Pero, de nuevo, es preciso observar que no le incumbe hallar soluciones concretas para antinomias concretas, sino averiguar en qué sentido y en qué medida se puede llegar a decisiones ante los conflictos antinómicos. La pretensión de solucionarlos puede corresponder a alguna determinada doctrina moral, o, en general, a la casuistica; pero no a la ética. En tal sentido es aplicable la concepción de Nicolai Hartmann acerca de esta disciplina: ella no enseña lo que debe hacerse en una situación dada, sino que investiga cómo está configurado lo que atañe al deber ser y al deber hacer, es decir, qué elementos distinguen al fenómeno moral de otros fenómenos. En la cuestión fundamental que pregunta qué debemos hacer, la ética no puede proporcionar una respuesta que determine o describa ese "qué"; se limita a indicar criterios que permitan reconocer el deber. No significa esto que ella se encuentre divorciada de las situaciones en que encarna la realidad moral, sino que es precisamente una visión en perspectiva, "a vuelo de pájaro", de esa realidad moral: es la actitud que consiste en observarla panorámicamente. La ética, según Hartmann, "no se inmiscuye en los conflictos de la vida, ni da preceptos referentes a ellos; no es un código de mandamientos y prohibiciones, como ocurre con el derecho. Se dirige justamente a lo que hay de creador en el hombre, desafián- 
dolo a que perciba o, por asi decir, a que adivine, en cada nuevo caso, lo que debe ocurrir aquí y ahora. La ética filosófica no es casuística y jamás le es lícito convertirse en algo semejante: con ello mataría en el hombre justamente aquello que le incumbe despertar y educar: lo creador, lo espontáneo, el íntimo contacto viviente del hombre con lo que debe ser, con lo valioso en si". ${ }^{1}$ En esto consiste, precisamente, su carácter de disciplina "práctica": en que ella educa y hace madurar la vida práctica del hombre, no proporcionándole reglas o esquemas fijos, sino ayudando a que el hombre se libere de toda tutela y se haga totalmente responsable de sus propios actos. Se dirige, pues, a lo creador que reside en la esencia humana, a lo que Hartmann llama "el demiurgo en el hombre". Si la ética investiga los conflictos, las antinomias morales, no lo hará, entonces, para indicar cómo se resuelve cada una de tales antinomias, sino para brindar al hombre un conocimiento más adecuado sobre sí mismo cuando tenga que afrontarlas.

Al decir que la antinomia constituye un problema ético, queremos significar que ella forma parte de la estructura del fenómeno moral. Dentro de la gran complejidad de éste, las relaciones antinómicas representan un elemento característico y sobresaliente, y aun podría añadirse: definitorio. Debe haber por tanto una parte de la ética que se ocupe especialmente de ese problema. En otras palabras: debe ser posible una ética de los conflictos. La Ética de Hartmann nos permite ver que una tal disciplina existe efectivamente. Su validez, sin embargo, es puesta en duda cada vez que se ponen en duda las antinomias morales mismas: la consideración teórica de éstas no podrá admitirse como sensata, y mucho menos como "rigurosa", alli donde, de un modo u otro, se afirme que los conflictos no son más que "seudopra blemas". Es curioso - pero muy comprensible en cuanto se observan los motivos de ese hecho- que en la filosofía de Kant, el gran pensador de las "antinomias" en el plano gnoseológico, no haya cabida para las antinomias en el terreno de la moral. Se ha señalado, con acierto, que, en todo "intelectualismo" ético, los conflictos morales no pueden ser interpretados sino como "ilusiones", como algo no real, como meras apariencias explicables por defectos del saber moral: una formulación clara, una captación precisa, harían desaparecer el conflicto. ${ }^{2}$ Como bien lo advierte $\mathrm{H}$. Nohl, ${ }^{3}$ este tipo de interpretaciones se encuentra en Christian Wolff - quien niega que dos obligaciones puedan oponerse-, o en Schleiermacher -quien reclama para la ética una "fórmula libre de colisiones" - o, en fin, en todo pensador que

1 Hartmann, N.: Ethik (Berlin, W. de Gruyter \& Co., H. Auflage, 1962, Einleitung, 2), p. 4. En adelante citaremos por esta edición, indicando, en cada caso, capítulo, pará. grafo y página.

2 Cf. Pustet, Fritz: Gewissenskonflikt und Entscheidung (Regensburg, Verlag Friedrich Pustet, 1955), p. 12.

3 Cf. Nohl, Hermann: Introducción a la ética (trad. M. Frenk, México, Fondo de Cultura Económica, 1952), pp. 178 ss. 
crea en una dirección unitaria de la moralidad. El caso de Kant es, en tal sentido, el más característico y el más importante. En su ética, lo único bueno en sí mismo es la "buena voluntad", o sea, la voluntad regida por el "deber". El sentido de lo "bueno" reside exclusivamente en una determinada estructura formal: la forma de legalidad universal que pueda ser alcanzada por el objeto del querer. Kant lo indica con el "canon de juicio moral" ("se tiene que poder querer que una máxima de nuestra acción se convierta en ley universal"), dando así univocidad al concepto de moralidad, y excluyendo, al mismo tiempo, toda antinomia entre bien y bien, todo "conflicto de deberes". Si la voluntad es el elemento que da la pauta acerca de lo que en cada caso es bueno, el conflicto pierde todo sentido. Pero lo que Kant no ha visto es precisamente el hecho de que la "buena voluntad" puede, en determinadas situaciones, no saber hacia dónde debe dirigir la acción. La ética kantiana es coherente consigo misma; su falla radica -como se ha señalado especialmente desde Scheler- en no atender a los contenidos del obrar. Estos contenidos pueden, a veces, exigir realizaciones diversas que son incompatibles.

Toda forma de "rigorismo" ético, por otra parte, hace necesariamente caso omiso del conflicto. Esto ocurre no sólo en la ética kantiana, sino también cada vez que se interpreta el obrar humano según esquemas rígidos que dan lugar al fanatismo moral. Su punto débil se halla en la falta de visión del dinamismo propio de la vida ética, en la cual todo fluye y se renueva, provocando a menudo situaciones conflictuales. Pero, paradójicamente, el conflicto también es desconocido por una actitud que constituye el polo opuesto del "rigorismo": la desidia o indiferencia moral. Esto puede hallarse, por cierto, como mera falta de responsabilidad; pero, en ocasiones, proviene de un sistema doctrinario. Es el caso de los antiguos cínicos, para

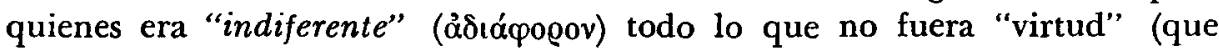
había de cultivarse) o "vicio" (que había de combatirse). Al margen de la inevitable inconsecuencia a que conduce esta teoría (al negarse toda relación de preferibilidad entre los bienes extramorales, el ámbito de lo moral pierde su contenido), ella excluye también toda posibilidad de conflicto: no tiene sentido una oposición entre cosas indiferentes.

Sin embargo, la negación no es la única actitud errónea ante el problema de las antinomias morales. Ella tiene su reverso en otra posición extrema, que consiste en ver conflictos en todas partes. Se trata de la exageración de la escrupulosidad que incide en la voluntad humana inhibiendo la capacidad de tomar decisiones y asumirlas. Como ha señalado A. Kolnai, "muchos aparentes antagonismos son sólo quimeras (Ausgeburten) de la debilidad moral, de la comodidad o del fariseísmo".4 Es necesario reconocer que hay

4 Kolnai, Aurel: Der ethische Wert und die Wirklichkeit (Freiburg, Herder \& Co., 1927), p. 22. 
situaciones en que se tropieza con la apariencia conflictual; pero en las cuales el análisis objetivo y desprejuiciado puede hallar siempre una salida con relativa facilidad. No se puede hablar en tales casos de verdaderas "antinomias" morales, ya que éstas tienen, como veremos, carácter aporético. La vida humana está poblada de situaciones dificiles, de situaciones en que es inevitable elegir y hacerse cargo de lo elegido. Elegir implica también una renuncia: se excluye simultáneamente lo no elegido y que se presentaba como una posibilidad ocasional. Casi podríamos decir, sin exageración, que la vida humana es una cadena ininterrumpida de situaciones de ese tipo. Pero ellas no son necesariamente antinómicas. Una ética de los conflictos tiene que empezar por la distinción entre conflictos auténticos y seudoconflictos. Constituye de por sí un problema no despreciable la dificultad de hallar criterios para reconocer unos y otros; pero ya habremos andado un paso si admitimos esa dualidad. Con este problema se vincula el de si cada "conflicto de conciencia" corresponde efectivamente a lo que podríamos denominar un conflicto "objetivo". La llamada "conciencia moral" o "voz de la conciencia" (el Gewissen de los alemanes) es una extraña instancia, todavía no suficientemente aclarada por psicólogos ni por moralistas ni por filósofos, que nos indica cómo debemos (o, al menos, deberiamos) actuar y juzgar en cada situación. No siempre sus indicaciones se imponen a nuestra voluntad: en ésta intervienen también otros resortes, que muy a menudo nos apartan del "deber". Aquí es donde Kant vio con mucha claridad (aun cuando no advirtió tampoco toda la complejidad del Gewissen): no puede haber verdadero conflicto entre lo que se nos presenta como "deber" y lo que nos aparta de él. Pero hay ocasiones en que el lenguaje con que nos habla esa "conciencia moral" no es unívoco, es decir, ocasiones en que se nos presentan simultáneamente exigencias distintas que se excluyen mutuamente. La "voz de la conciencia" es entonces un dúo, o incluso todo un coro de voces que no armonizan: estamos ante un "conflicto de conciencia". Cada una de las distintas voces pretende imponérsenos; todas hablan en nombre del "deber", y sin embargo son antagónicas, rivalizan, están en colisión. Advertimos, por tanto, que cualquiera sea la decisión, ella lesionará una exigencia moral, un determinado "deber"; y, sin embargo, es ineludible decidir. La cuestión que se plantea es la de si frente a todo "conflicto de conciencia" hay un "conflicto de valores". Esto nos remite al problema central de la axiologia — no siempre correctamente formulado-:5 el de la "objetividad" de los valores. Quien la

5 La mayor parte de las teorías axiológicas "objetivistas" han supuesto que la "objetividad del valor" debía fundamentarse describiendo los valores como un tipo especial de "objetos". Scheler, y sobre todo Hartmann, los han ubicado entonces entre los objetos ideales, ya que no es posible que sean "reales" (porque implicarían temporalidad). Nos parece que en esto se confunde "objetividad" con "objetidad". Para que los valores sean "objetivos" no necesitan ser "objetos": la "objetividad axiológica" alude simplemente a la posibilidad de valoraciones no arbitrarias, valoraciones que nos proporcionen una "evi- 
niegue, tendrá que afirmar que los "conflictos de conciencia" provienen de una ilusión, o que dependen de la manera como cada individuo interpreta los hechos. Es decir, estará en la posición, ya mencionada, de quien ve todo conflicto como un "seudoproblema". Podrá, a lo sumo, considerarlos como una cuestión psicológica $\longrightarrow$ psicopatológica-, que nada tiene que ver con la ética. Quien, por el contrario, afirme la "objetividad" de los valores, no tendrá resuelto con ello el problema de la vinculación entre los "conflictos de valores" y los "conflictos de conciencia". Antes, deberá preguntarse si los diversos valores "objetivos" pueden verdaderamente oponerse entre sí, o sea, si hay, en definitiva, "conflictos de valores", "antinomias axiológicas". $\mathrm{Si}$ a esto se responde negativamente, estamos de nuevo en lo anterior: los conflictos son ilusorios. La negación del conflicto no es incompatible con la afirmación de la "objetividad" axiológica. Pero si, en cambio, se sostiene que los valores objetivos pueden entrar en "colisión", habrá, por fin, la posibilidad de que por lo menos algunos "conflictos de conciencia" no sean meras ilusiones subjetivas. Éste es el supuesto imprescindible para el desarrollo de una ética del conflicto. Sólo a partir de aquí se hace la referida distinción entre "conflictos" y "seudoconflictos", o entre conflictos "auténticos" e "inauténticos". Aclarar esa distinción significa determinar los caracteres de unos y otros. Ello es tarea reservada a la ética.

\section{El método en las investigaciones éticas de Hartmann}

Ya hemos indicado que la Ética de Nicolai Hartmann puede entenderse como una ética de los conflictos. Las "antinomias" no sólo ocupan en ella un lugar central y decisivo, sino que conducen, por así decir, el desarrollo de cada uno de los problemas éticos tratados por el filósofo. Ello responde a la concepción metodológica manifestada también en sus otras obras. El "método" hartmanniano aplicado en los distintos ámbitos de su investigación filosófica consta de tres pasos fundamentales: fenomenologia, aporética y teoria." La descripción "fenomenológica" previa es para Hartmann el fundamento imprescindible para tener la certeza de que el investigador se atiene a los hechos; pero debe entenderse dentro del marco de una crítica dirigida contra la "fenomenología profesional": 7 Hartmann aclaró reiteradamente que no se consideraba a sí mismo como un "fenomenólogo". La descripción feno-

dencia". Es esto, a nuestro juicio, lo que debe discutirse y no la cuestión, ociosa, de si haył o no valores "fuera" del sujeto valorante.

6 Acerca del método de Hartmann, cf. Hülsmann, Heinz: Die Methode in der Philosophie Nicolai Hartmanns (Düsseldorf, L. Schwann, 1959). Véanse también los artículos: de Hartmann: Zur Methode der Philosophiegeschichte y Systematische Methode (ambos incluidos en Kleinere Schriften, Bd. III, Berlin, W. de Gruyter \& Co., 1958).

7 Cf., por ejemplo, el interesante artículo de Landmann, Michael: "Nicolai Hartmann and Phenomenology". (En: Philosophy and Phenomenological Research, vol. III, No 4, 1943). 
menológica es indispensable; pero también insuficiente: en el problema del conocimiento, por ejemplo, la fenomenología no puede plantearse la cuestión acerca de cómo el sujeto aprehende un ente que lo trasciende. ${ }^{8}$ Este tipo de dificultades requiere, para su planteamiento, un segundo paso metodológico: la aporética, que tiene una importancia capital en todo el pensamiento de Hartmann. Se trata, en efecto, de un pensamiento "problematizador", un pensamiento que intenta constantemente ser "fiel al problema", y no al "sistema". El rechazo de lo "constructivo" y la minuciosidad en la formulación de los problemas, de las aporias, son el signo permanente de esta filosofía, en la cual el "pensamiento sistemático" -que no ha de confundirse con el "sistema"- está puesto al servicio de una recuperación de las cuestiones fundamentales en su originalidad. La aporética es, por tanto, algo más que un paso en el método de Hartmann: es el núcleo mismo de su filosofar, aun cuando el propio Hartmann reconozca que no es "lo definitivo". Esto último se halla, por cierto, en el tercer paso, la "teoría", que consiste ya en una búsqueda de soluciones; pero esa búsqueda, precisamente, es consciente de sus limitaciones: toda aporia contiene un "resto insoluble". Retomando el sentido originario, etimológico, de la palabra "teoria", Hartmann la entiende como una "contemplación", por medio de la cual se ve el problema desde todas sus aristas. La "teoría", entonces, no equivale a "doctrina", ni a "sistema", por más que resida en ella una natural inclinación hacia esto. Se trata, simplemente, de un "avance" hacia las soluciones, y ese avance se lleva a cabo mediante una contemplación amplia y penetrativa de los problemas. Vemos, pues, que - aunque Hartmann no lo diga expresamente- la "teoría" está concebida también, al fin y al cabo, como "aporética": representa algo así como la culminación de esta última, aun cuando se distinga de ella por serle lícita ya una "toma de posición" (mientras que la aporética, al igual que la fenomenologia, debe mantenerse, según Hartmann, "más acá de realismo e idealismo"). Esa "toma de posición" es, en todo caso, un modo de "ver" más claramente, no con la pretensión de haber arribado a soluciones definitivas, sino para reducir a un "mínimo" ese resto insoluble que siempre ha de tenerse presente. "Teoría" es, así, el "tratamiento" (Behandlung) de las "aporías". Tanto ella como la aporética que la precede son en conjunto una tarea "metafísica", término, este último, que también posee en Hartmann una significación muy precisa: alude justamente al reconocimiento de ámbitos irracionales o "transinteligibles", es decir, a la actitud que consiste en atenerse a soluciones meramente aproximativas y provisorias, ya que los verdaderos problemas filosóficos no son jamás solubles en su totalidad. Por

8 Cf. Grundzüge einer Metaphysik der Erkenntnis (4. Auflage, Berlin, w. de Gruyter \& Co., 1949), Cap. 7.a, pp. $7^{6}$ ss. y cap. 20, pp. 169 ss. Ver también Zur Grundlegung der Ontologie (3. Auflage, Meisenheim a. Glan, A. Hain, 1948), Einleitung, 1 1, p. 16, y cap. 24., pp. 162 ss. 
lo mismo, interesan más ellos mismos, como problemas, que las soluciones que puedan proponerse. A través de sus múltiples investigaciones de la historia de la filosofía, ha tratado Hartmann de mostrar cómo lo verdaderamente "imperecedero" y "suprahistórico" en el pensamiento de los filósofos clásicos no ha provenido de la especulación "constructiva", sino de la ordenada investigación de los problemas. ${ }^{9}$

La problematización es, entonces, el módulo propio de la filosofía hartmanniana. Ella representa un replanteamiento de todos los viejos problemas, y en esto consiste, paradójicamente, su "actualidad". Es una ontología "crítica", eliminadora de viejos prejuicios: vuelve decididamente a los temas de la metafísica antigua, pero tratándolos con el instrumento crítico proporcionado por la filosofía moderna. Francisco Romero ha escrito, con razón, que Hartmann cuenta "con toda la conciencia filosófica de Occidente", y agrega: "su actualidad depende de su aptitud para apoderarse de los últimos hilos, prolongarlos y urdir con ellos su trama, prosiguiendo por su cuenta la tarea tantas veces secular con un agudo sentido de la continuidad histórica, de la ininterrumpida solidaridad de las generaciones". 10

Los caracteres que hemos señalado como propios de la filosofía de Hartmann en general, se encuentran también ejemplificados en su Ética, que nos interesa considerar especialmente. Hallamos aquí lo que podríamos denominar una gran aporética de los problemas éticos, $\mathrm{y}$, dado que toda aporética es, como vimos, una tarea "metafísica", estamos ante una metafísica de la moral. Por cierto, también aquí se aplica el método mencionado, y la fenomenología sirve como punto de partida. Por esta razón es lícito considerar a Hartmann, hasta cierto punto, como un representante de la "fenomenología del valor" (la Wertphänomenologie), y, por ende, como un continuador de Max Scheler, con quien se emparenta, sin duda, en más de un aspecto. Pero, de nuevo, se trata de ese punto de partida que él estima necesario para no contradecir los fenómenos, para atenerse a los hechos, evitando toda "construcción" previa. Sus análisis se prolongan inmediatamente hacia los elementos problemáticos, hacia las "aporias", que tienen aquí el carácter de "antinomias". El criterio de la problematización le permite también una corrección crítica de las ideas expuestas por Scheler en su "ética material de los valores". Hartmann comienza indicando que la ética filosófica, interesada durante el siglo xix exclusivamente en los actos de la conciencia moral, experimentó "en nuestros días" una vuelta de la atención hacia los problemas del contenido ético. En esto consiste -afirma- "el mérito de

9 Esto puede encontrarse no sólo en los muchos trabajos de Hartmann sobre la historia de la filosofía (reunidos en gran parte en Kleinere Schriften, Bd. II, Berlin, W. de Gruyter \& Co., 1957), sino también en constantes referencias incluidas en sus concepciones gnoseológicas, ontológicas y éticas.

10 Romero, Francisco: Un fildsofo de la problematicidad (en Filosofia Contemporánea, $3^{\text {a }}$ ed., Buenos Aires, Losada, 1953, pp. 9-24), p. 11. 
Max Scheler", quien logró la sintesis de dos pensamientos fundamentales que hasta entonces se oponían: el carácter a priori de la ley moral kantiana y la multiplicidad axiológica divisada sólo desde lejos por Nietzsche. Éste no pudo evitar el relativismo, y Kant no había sabido contemplar el mundo de los valores. Scheler, en cambio, devuelve a lo a priori ético su contenido propio, y a la conciencia axiológica le muestra aquello que subsiste al cambio y a la relatividad de las valoraciones. De este modo -agrega Hartmann-, Scheler ha "mostrado" el camino correcto; pero nadie ha "recorrido" aún ese camino. Es necesario, para ello, sobrepasar a Scheler y alcanzar "una síntesis histórica de mayor estilo que la de Kant y Nietzsche": la síntesis de la ética antigua y la ética moderna. Hartmann ofrece su propia Ética como un posible "comienzo" en tal trabajo, cuya consumación encomienda al pensamiento filosófico actual. ${ }^{11}$

Hartmann sobrepasa también a Scheler en el desarrollo de una ontología de los valores, que éste a lo sumo había sugerido muy ambiguamente. Ambos arrancan del análisis fenomenológico del valor y de la crítica de las éticas relativistas y nominalistas: quieren poner a salvo la "objetividad" axiológica. El punto de partida y las intenciones, por tanto, son coincidentes. No puede negarse tampoco una mayor originalidad a los hallazgos de Scheler. Pero Hartmann lo supera en el examen claro y riguroso de la naturaleza especifica del valor. Ello le permite la elaboración de una axiología que -aun cuando ha sido objeto de abundantes críticas, muchas de ellas realmente justasrepresenta la culminación de esa corriente de pensamiento y un punto de referencia ineludible en toda seria investigación de los valores.

La estructura "antinómica" de la Ética se manifiesta desde el comienzo. Ya las mencionadas "síntesis" a que alude Hartmann en el prólogo, con respecto a la renovación que debe operarse en la disciplina, son una manera de "resolver" —en la medida limitada en que puede resolverse una "aporia"-situaciones antinómicas que enfrenta el investigador de los problemas éticos. Más abajo veremos cómo la "síntesis" es, para Hartmann, la única salida posible de una "antinomia". En la "Introducción" (Einleitung), donde Hartmann expone con claridad el sentido de su investigación, se explicitan también algunas de las aporias fundamentales con que ésta tropieza: mientras el saber teórico cuenta con la posibilidad de ser corroborado por la experiencia -en el caso de ser verdadero aquello que nos proporciona el conocimiento $a$ priori- o de ser rectificado por ella, el saber "práctico" propio de la ética no tiene este recurso. Lo "que se debe hacer" no puede esperar a la experiencia, ya que ésta consistiria aquí en la consumación del acto, y lo pregun-

11 Cf. Ethik, ed. cit., Vorwort (Prólogo a la $1^{\text {a }} \mathrm{ed}$.), pp. V ss. Veinticuatro años más tarde de estas afirmaciones, al publicarse en 1949 la $3^{a}$ ed. de la obra, Hartmann se quejaba, sin embargo, de que la situación de la ética seguía siendo la misma (cf. ibid., Vorwort zur dritten Auflage, p. X). 
tado es precisamente cómo éste ha de realizarse. El conocimiento ético es, necesariamente, un conocimiento a priori. La aporia consiste en que no sabemos cómo pueden alcanzarse los principios éticos, ni cómo podemos llegar a tener certeza de ellos, ya que aparecen siempre como cambiantes y discutibles. A esto corresponde el carácter "práctico" peculiar de la ética: los otros conocimientos "prácticos" (técnica, higiene, jurisprudencia, pedagogia) incluyen un saber sobre la propia meta, es decir, tienen ya supuestos sus fines y sólo interrogan por los medios para alcanzarlos. La ética, en cambio, tiene que mostrar y probar sus propios fines, que son supremos y absolutos, y no pueden entenderse a su vez como medios. ¿Cómo conocer, entonces, esos fines absolutos, si ellos no pueden ser inferidos de algo real ni tampoco pueden ser corroborados? Tal es la aporia contenida en la pregunta fundamental de la ética: "qué debemos hacer"; es una aporía que forma parte de la esencia de la ética como disciplina, y del saber moral en general. Ella plantea a su vez una "antonomia", ya que, pese a su insolubilidad, exige ser resuelta: es una cuestión que se ofrece no sólo al investigador, sino al hombre en cuanto persona moral. "Cada uno tiene que resolverla por sí mismo de alguna manera -escribe Hartmann-, y si no lo hace con el pensamiento, con seguridad deberá hacerlo con los hechos. Nadie puede dar un paso en la vida sin decidirse de un modo $u$ otro frente a esta aporia. Su gravedad es el correlato necesario de aquella dignidad de la autonomía, de aquel privilegio supremo que caracteriza precisamente al ethos del hombre." 12

La pregunta por el "deber hacer", sin embargo, no agota la problemática propia de la ética: el hombre tiene no sólo la obligación de "hacer" algo (lo valioso), sino también la de "participar" en la plenitud axiológica del mundo real. Es decir, la moralidad no se limita a la acción: comprende, además, las actitudes que se asumen frente a los valores, la "toma de posición" (Stellungsnahme), la "aprobación" o el "rechazo", la "veneración" o el "desprecio", el "amor" o el "odio". Es una "relación de tensión" (Spannungsverhältnis) entre el sentimiento y las cosas del mundo, algo que está presente incluso en la conciencia cognoscente - ya sea como "admiración", o "interés", etc.-, que, por eso, nunca es meramente teorética. Este aspecto del ethos no alude al "deber", ni exige decisiones graves; pero apela a la responsabilidad humana: quien no "toma posición" y se mantiene siempre "indiferente", no participa en nada, no comprende el sentido de las relaciones vitales, ni de las personas, situaciones o acontecimientos. Cuando falta la sensibilidad para esto, el mundo y la vida aparecen como desprovistos de toda significación. El "vacío interior" tiene su necesario correlato en un "vacío exterior", que parece teñir todo de monotonía. Con ello se desfigura la esencia misma del hombre; por eso la "participación" en la "plenitud" del mundo constituye también una exigencia de la moralidad. La ética

12 Ethik, Einleitung, 3., p. 7. 
filosofica, según Hartmann, ha olvidado muy a menudo este aspecto, deslumbrada por la otra exigencia, más actual y elemental: la del "deber hacer"; ha sido, así, unilateral, y ha influido deformando el ethos, más que formándolo. Vemos aquí un serio reproche de Hartmann a la ética kantiana: toda ética que se reduzca al deber, que sea meramente "imperativa", incurre en la grave falta de desatender aquella "plenitud". El "rigorismo" moral es ciego para los valores realizados, porque no puede concebir lo valioso más que como "deber ser", y por tanto, como algo que no "es". Hay en tal actitud un gran "desconocimiento de la vida", y una enorme "ingratitud"; esa ética implica "encandilamiento moral" y "ceguera axiológica" (Wertblindheit), y no hay que extrañarse de que históricamente conduzca al pesimismo: la vida se hace insoportable en un mundo sin valores. ${ }^{13}$ Hay, pues, en la ética, una segunda cuestión fundamental: la que se refiere a la esencia de lo valioso, es decir, la pregunta que interroga por el "bien" en general. Se trata de una pregunta más amplia y más rica en contenido que la primera, a la que, en cierto modo, implica y subordina. Se debe, en general, a la "estrechez de la conciencia axiológica" el hecho de que el hombre "pase de largo" frente a muchos contenidos de valor que le ofrecen los datos de la realidad. Ello es particularmente notable en nuestra época, porque la "conciencia axiológica" parece estar dormida. El hombre moderno se caracteriza, según Hartmann, por su constante precipitación y por su apatía o insensibilidad: se ha vuelto incapaz de admirarse, de asombrarse profundamente; y lo peor radica en que considera esa incapacidad como una "virtud". Situaciones similares se han dado otras veces en la historia, siempre como síntoma de decadencia. A lo que se hunde por propia voluntad, no puede impedírsele el hundimiento; pero en toda decadencia habita también el germen de una nueva vida, joven y sana. El "hombre ético" - cuyos caracteres son diametralmente opuestos a los del hombre precipitado y apático- no es, pues, una quimera, sino algo que está dormido; Hartmann le adjudica a la ética la tarea de despertarlo. La "nueva ética" debe constituir, según esto, un "nuevo ethos", una manera de recuperar aquello que puede calificarse como el afecto filosófico originario: el pathos socrático del asombro. ${ }^{14}$

En todo esto advertimos una especie de plan o programa para el desarrollo de las investigaciones éticas. La apariencia, por así decir, mesiánica, puede explicarse por el hecho de que tales investigaciones están encaminadas al conocimiento del "bien", conocimiento que, como ya lo señalara Nietzsche, no es aún patrimonio del hombre. Lo que nos importa destacar, de todos modos, es el carácter antinómico que ve Hartmann en el "reino axiológico" (Wertreich): ello se debe, como veremos, a la "pluridimensionalidad" de dicho "reino", e implica, por tanto, que en la búsqueda de ese "conocimiento

13 Cf. Ethik, Einleitung, 4., pp. 7-9.

14 Cf. Ethik, Einleitung, 8., pp. 16-17. 
del bien" no ha de suponerse necesariamente un valor supremo del cual dependan todos los demás. Vale decir, no es imprescindible postular un principio supremo y único para afirmar la posibilidad de la acción moral. La admisión de una pluralidad de valores que no se unifican mediante uno común a todos, sino que se hallan entre sí en múltiples relaciones, incluso la de "oposición", no suprime la moral práctica. Por el contrario: esa admisión permite comprender mejor la complejidad del fenómeno moral. Las morales "vigentes" no pueden evitar la forma de "monismo", pues de lo contrario caerían en la ambigüedad. Cada moral toma un determinado valor y lo coloca en la cúspide de una tabla, subordinando así a ese valor escogido todos los otros valores. Es la inevitable unilateralidad de cada moral, su "estrechez", debida a que se apoya siempre arbitrariamente en un determinado principio unificador. ${ }^{15}$ Este hecho explica también la historicidad de las morales: ellas son "vigentes", en efecto, hasta el momento en que son remplazadas por otras. El prejuicio de la "unidad" del bien condena a cada moral a la transitoriedad. También la reflexión ética ha sucumbido muy a menudo a la tentación del "monismo"; pero se trata de un prejuicio del que la ética debe liberarse: "Tanto en lo teórico como en lo práctico, todos los monismos son del tipo puramente constructivo. Surgen de una pretensión de unidad, propia del afán de comprender; pero no responden a ninguna condición de los fenómenos mismos." ${ }^{16}$ La verdadera "unidad" de la ética debe consistir, precisamente, en que ella pueda abarcar y explicar a todas las distintas morales. Debe también buscar la "unidad" propia del reino de valores; pero sin postular aquí una "armonia", pues entonces negaría las antinomias axiológicas (Wertantinomien) y pasaría por alto un problema que se halla en los fenómenos. Ante la multiplicidad de las morales no debe haber un monismo del valor, pero ante la multiplicidad de los valores hay que exigir un monismo de la ética. De tal modo, se deja abierta la cuestión acerca de si la unidad del todo está determinada por un valor o por algún principio de otra índole. "Tiene que haber - agrega Hartmann - una ideal tabla axiológica, unitaria y absoluta, por encima de la diversidad de las tablas axiológicas históricas." 17 Hay que superar la unilateralidad de los "ismos".

Nos conviene tener presentes las tres partes en que divide Hartmann su Ética: I) "La estructura del fenómeno ético" (Fenomenología de las costumbres); II) "El reino de los valores éticos" (Axiologia de las costumbres), y III) "El problema del libre arbitrio" (Metafísica de las costumbres). En la Fenomenología de las costumbres no se plantean aún exhaustivamente las "antinomias"; pero ya se dejan entrever. Hartmann aclara aqui que tanto fallan las éticas "normativas" como las puramente "contemplativas". A la

15 Cf. Ethik, Cap. 30. a, p. 288.

16 Ethik, Cap. 3o.c, p. 290.

17 Ethik, Cap. 3o. d, p. 293. Cf. también Cap. 4., pp. $3^{6}$ ss. 
ética corresponde, según él, una "normatividad indirecta": el conocimiento que ella proporciona no determina la conducta moral; pero enseña a ver los valores, que en sí mismos contienen exigencias, y de este modo incide indirectamente sobre dicha conducta. Lo "normativo", entonces, no es la ética misma, sino el objeto que ella estudia: los valores. La "unidad" de la ética, contrapuesta a la "multiplicidad" de las "morales", está determinada precisamente por la metódica investigación de los valores. Se trata de una reflexión ordenada, sobre la base del "sentimiento del valor" (Wertgefühl), que es la manera como se nos da el valor originariamente. En el conocimiento del valor hay que hablar, pues, de una "conciencia axiológica primaria" y otra "secundaria" o "reflexiva". ${ }^{18}$ La ética se ha extraviado a menudo por culpa del desconocimiento de la estructura propia del reino de los valores: es el caso de las distintas formas del eudemonismo y del utilitarismo, e incluso de la ética kantiana. El análisis fenomenológico muestra a los valores como "esencias" (Wesenheiten), independientes de los "bienes". Son "condiciones de posibilidad" de éstos; son a priori; son "absolutos" - aun cuando presentan una forma de "relatividad" que Hartmann analiza cuidadosamente-; tienen un "ser-en-sí ideal", y, finalmente, revisten el carácter de "principios". Hartmann extiende estos análisis a la esencia del "deber", y hace una serie de "consideraciones metafísicas" acerca de problemas que atañen a la teleología introducida por el hombre en el mundo real, a la persona y al "personalismo". La Axiología de las costumbres y la Metafísica de las costumbres contienen el planteamiento de las "antinomias" que se derivan de todos estos análisis fenomenológicos previos.

\section{La noción hartmanniana de "antinomia axiológica"}

En la Axiologia de las costumbres utiliza Hartmann el procedimiento aporético y desarrolla con él los más diversos problemas inherentes a los valores; en primer lugar, los que se refieren a la "tabla axiológica" (Werttafel). Es aquí donde opone la ya mencionada "pluridimensionalidad" del "reino de valores" a la jerarquía unilateral propuesta por Scheler y objeta los "criterios" con que éste pretendía fundamentarla. ${ }^{19}$ Continúa con las considera-

18 Cf. Ethik, Cap. 6., pp. 47 ss. Sobre la concepción hartmanniana del "conocimiento axiológico" véase la obra de Mayer, Emmanuel: Die Objektivität der Werterkenntnis bei Nicolai Hartmann (Meisenheim / Glan, A. Hain; "Monographien zur philosophischen Forschung", Bd. VIII, 1952).

19 Cf. Ethik, Caps. 26-29, pp. 250 ss. La consideración de estos aspectos nos exigiría un "excurso" demasiado vasto. Bástenos señalar que Hartmann rechaza en general todos esos "criterios" schelerianos, admitiendo sólo -y con reservas- el de la "profundidad de satisfacción" (Tiefe der Befriedigung). Ataca especialmente, en cambio, el de la "fundación" (Fundierung): Para Scheler los valores inferiores "se fundan" en los superiores (su "estar dados" depende del de éstos). Hartmann califica esto como un "intento de fundación al revés" (cf. Cap. 26. d, pp. 254 ss.). Le opone un pensamiento que es central en su ontología: 
ciones -ya mencionadas- acerca del problema del "valor supremo": no " niega el hecho de que pueda haberlo; pero sí que pueda aprehenderse.

La "pluridimensionalidad" del mundo axiológico supone también múltiples formas de relación entre los diversos valores: subsumpción, fundación, afinidad y discrepancia, relaciones de estructura y de materia, de "ordenación de altura", de interferencia, etc. Las relaciones de oposición y antagonismo son tan frecuentes como las de concordancia, y es preciso admitirlas, aun cuando representen el peligro de que nos encontremos con "antinomias axiológicas" insolubles para el "sentimiento axiológico". ${ }^{20}$ Ya en las descripciones de la Primera Parte de la obra dedica Hartmann un importante parágrafo al tema "Contradicciones teleológicas y conflictos axiológicos",21 indicando que la "conciencia axiológica" puede imponernos simultáneamente cometidos diversos que se hallan en pugna entre sí. Estamos entonces frente a una "pluralidad de fines", detrás de la cual reside, en definitiva, una pluralidad de valores: de ahí el "resquebrajamiento" (Vielspältigkeit) que se produce en el hombre cuando éste se propone fines y trata de lograrlos: es la ocasión en que tropieza con los "conflictos axiológicos". La vieja ética pretendía que el conflicto moral se reduce a un antagonismo entre "resortes" morales y antimorales (o también meramente extramorales) del hombre; por ejemplo, entre "deber" e "inclinación". Lo "antimoral" se imputaba, entonces, a la "esencia natural" humana, o a una innata "propensión al mal". Pero este tipo de conflictos constituye sólo una reducida parte de los problemas morales. También hay conflictos entre valores, que pueden oponerse sin perder por ello su carácter de "deber ser". El conflicto así originado no es ya un choque entre lo moral y lo antimoral, sino un antagonismo "intramoral". "La alternativa - dice Hartmann- no es aquí la que hay entre el pecado y el recto obrar, sino entre pecado y pecado. En ambos casos se lesiona un valor, y, a su vez, también en ambos se cumple un valor. Quien se encuentra en un conflicto así - y la vida coloca al hombre a cada paso ante tales conflictos-, no puede salir de él sin culpa". ${ }^{22}$ Este hecho representa

la ley categorial de la "fuerza", en virtud de la cual "fuerza" y "altura" varian inversamente: a mayor "fuerza", menor "altura", y viceversa. Esto rige tanto en los estratos de la realidad como en el reino de valores: los valores "inferiores" son los más "fuertes" y, por tanto, "fundan" a los superiores, es decir, éstos sólo pueden "darse" sobre la base de aquéllos. Una captación más precisa de las diferencias entre los valores cree ver Hartmann en la concepción de Dietrich von Hildebrand acerca de una particular "respuesta axiologica" (Wertantwort) -es decir, un tipo exclusivo de reacción emocional- para cada valor determinado. Aun así, de todos modos, no pueden aprehenderse todos los matices de la diferenciación; ésta es una de las tareas que debe emprender la investigación axiológica (cf. Cap. 29. c, p. 281). Hartmann ve un primer intento -y al mismo tiempo, un modelode una tal "fenomenologia de las respuestas axiológicas" ya en la Ética Nicomaquea de Aristóteles (cf. Cap. 29. d, pp. 282 ss.).

20 Cf. Ethik, Cap. 3o. d, p. 293.

21 Cf. Ethik, Cap. 22. c, pp. 212 ss.

22 Ethik, Cap. 22. c, pp. 213-214. 
una limitación de la teleología, es decir, de toda actividad dirigida a un fin, y asimismo del "proponerse" fines, e incluso de toda conciencia del valor, del juicio de valor y del contenido moral de valor. Hasta la libertad se ve aquí ante un límite: el hombre no crea ni puede suprimir estos conflictos. Y todavía más: "Ellos pondrian también un límite a la armonía propia de una divinamente perfecta providencia y predeterminación dominadora del mundo." ${ }^{23}$ Con tales consideraciones anticipa Hartmann los elementos de un fundamental problema "metafísico" del reino axiológico, cuyo planteamiento detallado desarrolla prolijamente en la segunda y la tercera parte del libro.

La concepción hartmanniana de los conflictos puede ponerse también de relieve si se la compara con la de Scheler. Tampoco a éste se le escapó el problema; pero lo habia visto desde otra perspectiva. Recordemos que la axiología scheleriana tiene su eje en la idea de una jerarquía axiológica "unilineal" o "unidimensional". Cada grupo de valores tiene, por así decir, su peldaño fijo en la escala de valores, de tal modo que, en un mismo nivel jerárquico, sólo pueden "oponerse" valores pertenecientes a un mismo grupo. La "oposición" entre valores de distinta altura puede resolverla el sujeto moral - la persona - en la medida en que posea la capacidad de aprehender los valores del caso en sus respectivas posiciones jerárquicas. La solución es entonces muy simple: consiste en optar por.el valor más alto. Scheler llama "preferir" (Vorziehen) al acto emocional que "capta" la altura jerárquica de un determinado valor. Trátase de un "acto particular del conocimiento axiológico","4 por el cual se aprehende el hecho de que ese valor es "más alto" que otro u otros. No se trata de que el valor sea "sentido" primero como valor particular y luego se lo "prefiera", sino que el "ser-más-alto" (Höhersein) de un valor está "dado" necesaria y exclusivamente en el "preferir".25 Tampoco hay que pensar que la superioridad de un valor significa que ese valor es "preferido"; pues, aunque dicha superioridad (o "ser más alto") se da, como decimos, sólo en el "preferir", se trata de una relación que atañe a la esencia de los valores. ${ }^{26}$ Esto hace que la jerarquía axiológica sea absoluta e "invariable", en tanto que las "reglas de preferencia" (Vor-

23 Ethik, Cap. 22, c, p. 214.

24 Scheler, Max: Der Formalismus in der Ethik und die materiale Wertethik (3. Aufl., Halle, Max Niemeyer, 1927) I Teil, II, B, 3, p. 84 .

25 Cf. loc. cit. Véase también ibid., II Teil, V, 2, p. 267. El acto del "preferir" no debe confundirse con el de "elegir" (Wählen), que es, por su partc, un "acto de tendencia" (Strebensakt). El "preferir" se realiza sin necesidad de que haya elección ni tendencia. Además, lo que se "elige" es siempre un "hacer" (Tun) que conduce al "fin" (Zweck) al que se tiende. Lo que se "prefiere", en cambio, puede ser un "bien" (preferir "empirico") o un "valor" (preferir "a priori"). Si alguien "elige" un fin que se funda en el valor "más bajo" (entre los que se enfrenten en una opción), lo hace, según Scheler, por una "ilusión del preferir". Scheler llama "posponer" (Nachsetzen) al acto por el cual se capta la "inferioridad" de un valor.

26 Cf. ibid., pp. $85-86$. 
zugsregeln) se presentan como históricamente variables. Aquí tenemos la base de la doctrina ética de Scheler. La "moralidad" es para él, en efecto, la realización de los valores "morales", es decir, los valores "bueno" y "malo". Éstos no ocupan un lugar determinado en la tabla jerárquica, porque precisamente se dan en las relaciones de la voluntad con dicha tabla: el "bien" moral se realiza en la coincidencia del valor "intentado" con el valor "preferido". Scheler se opone radicalmente a la idea kantiana de que los valores morales dependen del "deber ser" (Sollen). Pero está, por otra parte, de acuerdo con Kant, en que ellos no pueden ser las materias del acto realizador. ${ }^{27}$ En general, esta concepción scheleriana -de indudable originalidad e importancia para la ética y la axiología- tropieza con una dificultad: necesita recurrir imprescindiblemente a los conceptos de "ilusión" y "ceguera" axiológicas (Werttäuschung Wertblindheit), no sólo para explicar la diversidad fáctica de valoraciones y de tablas jerárquicas (lo cual también hace Hartmann), sino también para interpretar los conflictos de valores. En virtud de la mencionada escala unilineal, se omite la posibilidad de que dos o más valores, correspondientes a distintos grupos o "modalidades" axiológicas, se enfrenten dentro de una equivalencia jerárquica. Los conflictos de conciencia se deberán, por tanto, a "ilusiones del preferir", es decir, a deficiencias en la aprehensión de la jerarquía axiológica. Scheler ha tratado el problema de los conflictos en su interesante trabajo Acerca del fenómeno de lo trágico. ${ }^{28}$ Sostiene allí que lo trágico -fenómeno esencialmente "cósmico" y no meramente estético- se vincula con las relaciones conflictuales entre valores: alude a una "eficiencia" (Wirksamkeit) dirigida hacia la destrucción de un valor positivo, de una determinada altura jerárquica. Pero, además, la fuerza destructora debe representar, ella misma, un valor positivo. Ahora bien, lo "trágico" no es la destrucción en cuanto tal, sino la dirección hacia esa destrucción, a través de portadores de valores positivos que nunca pueden

27 Cf. ibid., I Teil, I, 2, p. 22. El valor moral se realiza cuando se intenta la realización de un valor de otro tipo, que ha sido "preferido" y que constituye entonces la "materia" de la realización moral (de ahí la denominación de "ética material de los valores"). El criterio para reconocer lo "bueno" y lo "malo" en la esfera de la voluntad consiste en "la coincidencia del valor intentado en la.realización con el valor de la preferencia (Vorzugswert), o, respectivamente, en el antagonismo con el valor de la posposición (Nachsetzungswert)" (loc. cit.). El acto moral, por tanto, es aquel que apunta a los valores preferidos y de ese modo realiza el valor moral. Este queda, pues, como dice Scheler, "a espaldas" del acto dirigido a la realización de los otros valores. Si la voluntad se dirigiera hacia la realización de valores morales, caería en una especie de "fariseísmo" es decir, en la búsqueda de la mera apariencia del bien, y el verdadero valor moral quedaria sin realizar. Contra esta tesis se han dirigido algunas críticas interesantes (cf. por ejemplo, Reiner, Hans: Vieja y nueva ética, trad. Luis G. San Miguel, Prólogo de José Luis L. Aranguren, Madrid, Rev. Occid., 1964, pp. 249 ss.).

28 Zum Phänomen des Tragischen (en Vom Umsturz der Werte, Bern, Franke, 1955, pp. 149-169). Hay trad. castellana: Acerca del fenómeno de lo trágico (en El santo, el genio, el héroe; trad. Elsa Tabernig, Buenos Aires, Nova, 1961). Citaremos por ambas ediciones. 
ser más altos que los valores que se trata de destruir, pero que deben ser, de todos modos, de una elevada altura. ${ }^{29}$ En el conflicto "trágico" sucede que no sólo todos "tienen razón", sino que cada una de las personas y fuerzas en lucha representa una razón igualmente sublime (desde el punto de vista moral), o cumple un deber igualmente elevado. No hay "tragicidad" cuando es un valor negativo el que se dirige a la destrucción de un valor positivo: cuando esto ocurre, estamos ante un "sinsentido", ante algo "irracional"; pero no ante lo "trágico". Esto último requiere que haya un antagonismo entre portadores de altos valores positivos. "Trágico - dice Scheler- es el 'conflicto' que reina por sí mismo dentro de los valores positivos y de sus portadores." 30 EI "héroe trágico" es aquel capaz de aprehender un valor superior a los que rigen en la moral de su comunidad o de su época, es decir, aquel cuya capacidad de "preferir" es mayor que la de los demás. Por ver "más allá" que el resto, está obligado a intentar la realización de valores que, para los otros, no aparecen como "superiores", sino tan sólo como algo que atenta contra los valores vigentes. Como la "moralidad", según vimos, consiste en la coincidencia del valor "preferido" con el "intentado", nos encontramos con que tanto el "héroe trágico", como aquellos que lo combaten (porque ven en él un peligro, una amenaza contra lo que dicta la "ley dominante"), actúan "moralmente". En este choque de dos fuerzas igualmente "morales" consiste precisamente lo "trágico". El "héroe trágico" es lo contrario del delincuente, pero su época carece de criterios para distinguirlo de éste. El reconocimiento de su carácter "heroico" sólo será posible cuando sus valores se hayan convertido en "moral vigente". Entretanto, el "héroe trágico" no puede eludir su culpa, si bien, precisamente por esta ineludibilidad, no se trata ya de una culpa "moral", sino de la "culpa trágica", o, como también la llama Scheler, "culpa inocente".31

Interesa, pues, señalar que, para Scheler siempre, de un modo u otro, el conflicto se explica por deficiencias del conocimiento axiológico: quien no tenga "ilusiones del preferir", por ejemplo, no tendrá por qué tener conflictos de conciencia; el medio social o la época que tuviera una perfecta capacidad de "preferir" (lo cual fácticamente es imposible debido a la "estrechez de la conciencia axiológica"), no tendría por qué combatir a los héroes; es más: no habría entonces "héroes trágicos". En definitiva: no habría conflictos. En todo esto, insistimos, está supuesta la jerarquía unilineal. Por eso Hartmann, que la niega, ve también los conflictos axiológicos desde un ángulo distinto. La "pluridimensionalidad" hace que la relación de "jerarquía", con respecto a determinados valores, sea insignificante, o no merezca considerarse por otros motivos (por ejemplo, porque se dé entre

29 Cf. ibid., p. 154; ed. castellana, p. 148 .

30 Ibid., p. 155; ed. cast. p. 149.

31 Cf. ibid., pp. 161 ss.; ed. cast. pp. 157 ss. 
esos valores, con mayor relevancia, otro tipo de relación), o, en fin, puede que esas diferencias de altura jerárquica sean inaprehensibles para la conciencia axiológica. Ésta, en efecto, según Hartmann, está mejor configurada para la captación de matices cualitativos de los distintos valores, que para la captación de las diferencias jerárquicas entre los mismos. El problema del conflicto tiene para Hartmann sus raíces en la efectiva oposición de los valores. El conflicto de conciencia no se debe -por lo menos, no necesita deberse- a deficiencias del conocimiento axiológico; puede constituir el resultado de la vivencia de un conflicto, de una "antinomia", entre los valores mismos. Por eso ha señalado Pustet, con razón, que, mientras para Scheler el problema del conflicto es un problema "gnoseológico", para Hartmann, en cambio, aparece en primer lugar como problema "ontológico", ya que concibe lo conflictual como algo inherente a la estructura del mundo axiológico. ${ }^{32}$ Para Hartmann, en efecto, no puede dudarse de que el "conflicto moral", por más variaciones con que pueda presentarse en las distintas situaciones de la vida, es testimonio de un antagonismo entre valor y valor, y no de uno entre valor y desvalor. ${ }^{33}$ "El conflicto -escribe- no tiene la forma de la alternativa lógica contradictoria, sino siempre la de una oposición de contrarios, en la que el acento es positivo (axiológicamente positivo) en ambos lados. Pero, por otra parte, a ello se enfrenta el hecho de que la conducta efectiva de la persona no puede decidirse simultáneamente a favor de los dos lados de la oposición: sólo puede obedecer a uno de los valores que están en juego, y lesionar al otro. La decisión de la voluntad, por tanto, se ve obligada a tratar esa oposición, en sí misma contraria, como contradictoria." 34 Esto limita las decisiones de la voluntad humana a dar la preferencia siempre a un valor por encima de los otros, es decir, a no ser más que una función de la conciencia de la jerarquía. Pero la dimensión jerárquica es sui generis e indefinible: no puede explicársela por referencias a otros tipos de dimensiones. El sentido propio de lo "superior" e "inferior" es "axiológicamente irreductible".

En la Segunda Sección de la Segunda Parte de la Ética (caps. 31-34) trata Hartmann la cuestión central con respecto a los conflictos de valores: las "oposiciones axiológicas más generales". Insiste aquí en señalar que los antagonismos entre lo moral y lo moral son más esenciales para las situaciones éticas que los que existen entre lo moral y lo antimoral: "En una situación en que el valor está contra el valor, no hay salida libre de culpa. En efecto, el hombre tampoco puede sustraerse a la decisión. Tiene que decidirse de un modo $\mathbf{u}$ otro, y también la inacción es decisión positiva. Esto quiere decir, precisamente, 'estar en situación': tener que elegir a toda costa. El

32 Cf. Pustet, Fr., op. cit., p. 96 .

33 Cf. Ethik, Cap. 28. c, p. 272.

34 Ethik, Cap. 28. c, pp. 272-273. 
hombre está, por tanto, en realidad, constantemente colocado ante la necesidad de resolver conflictos axiológicos, es decir, de decidirse de tal manera que pueda responder de la culpa. Su destino es no poder escapar de la culpa." ${ }_{35}$ En esta concepción de la culpa advertimos, pues, una radicalidad mayor que en la de Scheler. En Hartmann la culpa no depende simplemente del choque entre diversas capacidades del "preferir", sino que arraiga en la estructura antagónica propia del reino de los valores.

No es necesario, para que haya oposición entre valores, que ella constituya siempre un conflicto axiológico en el seno del reino axiológico ideal. Basta con que una situación concreta haga imposible que se satisfaga un determinado valor sin lesionar a otro: "También la situación es un factor constitutivo del conflicto." 36 Las auténticas antinomias son insolubles; pero el carácter antinómico tiene distinta fuerza en las distintas oposiciones de valores: en algunos casos éstos se aproximan a la unión; en otros, se apartan constantemente y hacen imposible toda "reconciliación". El problema de si, entonces, hay o no un punto de convergencia, es una cuestión "metafísica", ya que una tal unificación estaría, en todo caso, fuera de los límites de la cognoscibilidad. Aun así, si hubiera efectivamente esa convergencia, lo antinómico se reduciŕa a los conflictos de la conciencia axiológica. Pero también es posible que los valores en conflicto tampoco converjan en lo transinteligible de ese reino ideal: no se trataría, entonces, de "antinomias de la razón", sino de antinomias del ser-en-sí ideal. La investigación axiológica se halla, de todos modos, muy lejos de poder afirmar nada al respecto. Pero lo cierto es que, frente a los conflictos, el hombre tiene que hallar decisiones, y de hecho las halla, por más unilaterales o incorrectas que sean. Esto significa que constantemente surgen nuevos intentos de solucionar el conflicto.

Los antagonismos axiológicos constituyen, según Hartmann, un sistema pluridimensional análogo al de los grandes antagonismos categoriales del ser. Por eso piensa que se los puede estudiar en relación con el esquema general de las categorías fundamentales: cantidad, cualidad, relación y modalidad. Distingue, entonces, oposiciones axiológicas "modales", "relacionales" y "cualitativo-cuantitativas", a cada una de las cuales dedica un importante capítulo. Dado que en el presente trabajo intentamos tan sólo mostrar cómo intervienen las antinomias (y el pensamiento antinómico) en la estructuración de la ética hartmanniana, podemos eximirnos de una consideración detallada de estas antinomias, que exigiría más espacio del disponible. Nos limitaremos, pues, a señalar las más importantes de cada grupo:

I. Las oposiciones modales comprenden, en primer lugar, la "antinomia axiológica de necesidad y libertad": Hay una "necesidad" propia del "deber ser" que caracteriza a los valores. A diferencia de la necesidad "ontológica", 
la "axiológica" es independiente de la "posibilidad", y por eso los valores tienen independencia del ser y no-ser reales. Esta "necesidad" es también, en sí misma, un valor, ya que proporciona a los valores su dignidad específica y la validez general que los caracteriza. A ella se opone, sin embargo, el valor de la "libertad". Es cierto que los valores "exigen" ser realizados. Pero su manera de exigir no determina, por sí sola, la conducta de la persona. Ésta es libre de cumplir o no con esa "exigencia". La "libertad" de la persona frente al valor es, a su vez, un valor fundamental para la moralidad. Pero también la relación antinómica misma es "valiosa".37

La otra antinomia importante de este grupo es la que se da entre el "ser y no-ser real de los valores": tanto el uno como el otro son, por su parte, valores. Como ya lo habían señalado antes Brentano y Scheler, reconoce Hartmann que "la existencia de un valor positivo es, en sí misma, un valor positivo". Pero también la "no-existencia" de un valor es un valor positivo (y no sólo "negativo" como lo veían Brentano y Scheler), ya que la "realización" de un valor (y el intento dirigido a esa realización) sólo es posible cuando y donde ese valor es irreal. La irrealidad misma constituye, entonces, un valor fundamental para la persona, a la que permite el acto de la realización moral. La antinomia es insoluble.

II. Las antinomias relacionales pueden ejemplificarse, ante todo, con la llamada "antinomia del portador de valor" (Wertträger): Cada portador de valor es también un valor por ser la condición de la realidad de aquel valor que se encarna en él. Pero, en la realidad ética, se presenta una dualidad del portador, correspondiente a la dualidad de valores que allí entran en juego. EI valor "intentado" y el valor de la intención (valor moral) tienen portadores distintos: uno está en el objeto; el otro en el sujeto de la intención. La antinomia consiste en que el objeto y el sujeto de una misma intención son portadores de valores distintos. Pero este conflicto puede resolverse cuando se advierte que la persona -que es el sujeto moral, el sujeto de la intención- también puede ser "objeto" moral, en el sentido de que "hacer el bien" o "hacer el mal" significa hacérselo "a alguien", ya se trate de una persona individual o social, y se haga directa o indirectamente. "Este dativus ethicus - dice Hartmann- acompaña toda conducta humana y es constitutivo para el valor y desvalor de la conducta." 38 El sujeto personal está, de tal modo, incluido en el contenido axiológico del objeto intentado. Por otra parte, todo lo valioso, e incluso lo moralmente valioso, tienen carácter de objeto axiológico en la medida en que haya de ello una conciencia axiológica. Por tanto, los propios valores de la persona muestran, desde esta perspectiva, carácter de valores de objetos, y tienen que poder ser objeto de actos morales. En consecuencia, el sujeto personal es también en este sentido

37 Cf. Ethik, Cap. 32. a, pp. 299 ss.

38 Ethik, Cap. 33. a, p. 305. 
un objeto de valor. De tal modo coinciden el sujeto y el objeto de la intención. Sin embargo, lo antinómico de la relación se expresa en el hecho de que las clases axiológicas de valores de objeto y valores de sujeto son distintas: los primeros se realizan en el éxito (Erfolg); los últimos, en la disposición de ánimo (Gesinnung). Pero también en este respecto las clases de valor pueden "engranarse": también el "éxito" corresponde a los sujetos morales, y una "disposición de ánimo" puede ser materia del éxito. En esta relación debe entenderse la antigua tesis de que la virtud es el "bien más alto": los supremos valores de bienes son los valores de virtud. ${ }^{39}$

Otra antinomia "relacional" es la que se establece entre actividad e "inercia" (Trägheit). El valor de la actividad es un valor del "estar dirigido hacia fuera de si" (Aussersichgerichtetsein), en el que la sustancia moral se trasciende a sí misma. El valor, para realizarse, necesita de la actividad del sujeto personal. Pero si éste se redujera a pura actividad, se disolvería, desaparecería. Debe haber, por tanto, en la esencia moral de la persona, algo que sea permanente, que resista a las tendencias, pero no de un modo meramente pasivo, sino como una contratendencia orientada a la conservación (Erhaltung), a la perseverancia (Beharrung), es decir, una "fuerza de inercia" (Trägheitskraft) en el ámbito moral. ${ }^{40}$ De tal modo se oponen el valor de la "actividad" y el de la "inercia": es valioso lo que conduce a la realización de un valor; pero también es valioso lo que conserva un valor realizado.

Hay también una oposición axiológica "relacional" entre "altura" y "anchura", es decir, entre la realización máxima de un valor único y la realización simultánea y compensatoria de diversos valores. Lo primero es propio de cada moral vigente: en una determinada unidad de la dirección de la tendencia crece la sustancia ética. Lo segundo permite el desarrollo de todo contenido axiológico accesible: hasta los contenidos heterogéneos pueden unificarse mediante la síntesis.

"Armonía" y "conflicto" son axiológicamente antagónicos. Frente al valor propio de lo armonioso, que representa una concordancia estática, se encuentra el valor del principio dinámico manifestado en la pugna, en la colisión: la repercusión ética de lo que Heráclito llamaba la "guerra" y que consideraba como "padre y rey" de todas las cosas. El "conflicto" es, en sí mismo, valioso, porque permite el movimiento y el avance en el ámbito de lo moral, en el mismo sentido en que, en el terreno del conocimiento, el "problema" es valioso porque permite el progreso del conocimiento. Lo moral consiste precisamente en afrontar conflictos, no en huir de ellos. ${ }^{41}$

39 Cf. Ethik, Cap. 3g. a, p. go6.

40 Cf. Ethik, Cap. 33. b, p. 307.

41 Cf. Ethik, Cap. 33.d, p. 311. Hay que señalar que, según Hartmann, este antagonismo no constituye en principio una auténtica "antinomia", ya que se trata de instancias que pueden equilibrarse. Pero los conflictos que se presentan en situaciones concretas pueden romper todo equilibrio y armonía, y entonces resulta una verdadera antinomia axio- 
Dentro de todo tipo de "armonía" o de "conflicto" se abre, por su parte, la oposición entre "simplicidad" y "complejidad". No se trata ya de un antagonismo de lo unitario con lo discrepante, sino de la unidad indiferenciada con la unidad diferenciada. La "simplicidad" es valiosa porque implica probidad, naturalidad, sencillez. Se vincula con los valores de la inocencia y la pureza. Pero la "simplicidad" puede implicar una conducta unilateral frente al conflicto, produciendo incluso una grave lesión a un determinado valor. La "complejidad" ética, en cambio, permite la atención a la multiplicidad axiológica. Representa una unidad secundaria, no ya originaria, como la de la "simplicidad", pero orientada hacia la madurez moral.

III. Hartmann trata, por fin, conjuntamente, las oposiciones cualitativas y cuantitativas. Se trata de los conflictos que se dan, por ejemplo, entre universalidad $e$ individualidad, o entre totalidad $e$ individuo. Tienen carácter "cualitativo" cuando se refieren a la manera de validez de los valores que entran en juego, es decir, cuando no interesan la "extensión", sino la "comprehensión", el contenido. Lo que posee validez universal es, por ello mismo, valioso; pero hay también un valor propio de lo que es individual e irrepetible. El Derecho, por ejemplo, es valioso por su universalidad: igualdad de todas las personas ante la ley. Cualitativamente se le opone el valor de la persona individual, valor que es tanto más alto cuanto mayores son los caracteres distintivos que posee. El sujeto moral puede experimentar la antinomia de universalidad e individualidad bajo la forma de dos exigencias opuestas: la de obrar "como harian todos" - o como "deberian" hacerlo (por ejemplo, en el sentido del "imperativo categórico") - y la de obrar de acuerdo con los dictados de su conciencia personal. La antinomia entre totalidad e individuo, en cambio, es "cuantitativa": mientras la universalidad se refería a la igualdad de todos los casos, la totalidad tiene que ver con la reunión de ellos en una unidad mayor y superior. Y mientras la individualidad aludía a lo característico del caso, el individuo es el caso mismo, con independencia de su parecido con otros casos. La antinomia "cuantitativa" se muestra, por ejemplo, en la oposición entre doctrinas socialistas e individualistas.

La única "salida" de una antinomia axiológica puede encontrarse en la sintesis. Pero ésta no siempre anula la antinomia: los valores opuestos se mantienen, por lo general, en su relación antinómica y tienden a excluirse mutuamente. Pero el concepto hartmanniano de "antinomia axiológica"

lógica. En toda realidad ética se enfrentan esas dos tendencias. Por encima de cada equilibrio armónico surgen nuevos conflictos, que, a su vez, exigen solución, atrayendo nuevas formas de equilibrio. La tendencia de ruptura y la tendencia de coordinación son constantes y se enfrentan siempre, formando un nuevo equilibrio de más alto orden, que es, simultáneamente, un desequilibrio, una dinámica de más alto orden. En estas formas se desenvuelve la vida de la realidad ética (Cf. p. 312). 
tiene, en general, su complemento, en el de "síntesis axiológica", de particular importancia en la teoría de Hartmann sobre las "virtudes". Éstas representan, en su mayor parte, "síntesis" de valores; pero, a su vez, unas virtudes pueden entrar en conflicto con otras.

Dentro de la compleja clasificación hartmanniana de los distintos valores, las virtudes ocupan el lugar de valores éticos "especiales" (frente a los "fundamentales", que Hartmann reduce a cuatro: lo "bueno", lo "noble", la "plenitud" y la "pureza"). El tratamiento de todos los valores presenta constantemente la consideración sobre los conflictos como una especie de hilo conductor, que sirve a Hartmann para el planteamiento de los muchos y diversos problemas. La "aporética" empleada para el análisis de los fenómenos de la moralidad es una "antinómica". Las virtudes son entendidas como "valores de la conducta humana", y comprenden una gran variedad, que es correspondiente a la variedad de formas de dicha conducta. Es imposible trazar una tabla completa de las virtudes. La investigación ética debe limitarse, según Hartmann, a aquellas que la conciencia axiológica de la época ha hecho aprehensibles. ${ }^{42}$ La perspectiva histórica permite distinguir varios grupos de virtudes, que pueden reducirse a tres, cada uno de los cuales (en especial los dos primeros) tiene un valor fundamental: I) virtudes de los antiguos: justicia (valor fundamental), sabiduría, valentía, autodominio, y las virtudes "aristotélicas"; II) virtudes "cristianas": amor al prójimo (valor fundamental), veracidad, fidelidad, confianza, fe, humildad, etc., y III) virtudes como la del "amor al lejano" (Fernstenliebe) -descubierta por Nietzsche-, el sacrificio, la personalidad, el amor personal, etc. Hartmann dedica a todas ellas minuciosos análisis, en los cuales no podemos detenernos. En todos los casos, las confrontaciones nos muestran importantes antagonismos: cometer injusticia y padecerla, legalidad y moralidad, amor al prójimo y justicia, veracidad y "mentira forzosa" (Notlüge), humildad y orgullo, "amor al prójimo" y "amor al lejano", etc. La estructura antinómica constituye también la columna vertebral en esta concepción de las virtudes.

La Sección VIII de la Segunda Parte está dedicada a la "legalidad" (Gesetzlichkeit) de la tabla axiológica, es decir, al sistema de leyes que rigen en el reino de los valores. Allí son considerados los distintos tipos de rela-

42 Cf. Ethik, Cap. 43, p. 417. Esta concepción de la artificialidad de toda clasificación fija y cerrada de las virtudes ha sido luego desarrollada admirablemente por O. Fr. Bollnow en su obra Wesen und Wandel der Tugenden (Frankfurt, Ulstein, 1958. Hay versión castellana de Lucio García Ortega, con Prólogo de José L. L. Aranguren: Esencia y cambios de las virtudes, Madrid, Rev. de Occidente, 1960). Hartmann considera también que otro error de la ética tradicional ha consistido en no limitarse a una descripción de las virtudes, sino en pretender indicar además las maneras de su realización, sin tener en cuenta que nadie se vuelve "bueno" a través de una instrucción. Ello ha trivializado y desacrcditado -agrega - las palabras "moral" y "virtud", convirtiéndolas en algo aburrido y ridículo. A la ética no. le incumbe "moralizar"; pero sí puede mostrar los valores morales. (Cf. Ethik, pp. 417-418). 
ciones axiológicas, y el capítulo 6 i trata en especial la relación de oposición y la "síntesis axiológica". Hay, según Hartmann, cinco tipos de oposición: r) valor-indiferencia axiológica, 2) desvalor-indiferencia axiológica, 3) valordesvalor, 4) valor-valor y 5) desvalor-desvalor. La tabla puede reducirse, sin embargo, a los tres últimos, que a su vez se interrelacionan y son exponibles en un cuadrado axiológico de oposiciones. ${ }^{43}$ Esto es de especial importancia, ya que sirve a Hartmann para una interesante interpretación de la teoría aristotélica de la $\mu \varepsilon \sigma o ́ t \eta 5$. De ella se ocupa ya en el capítulo 48 , dedicado a las "virtudes aristotélicas". Destaca, en primer lugar, la afirmación del propio Aristóteles (Ética Nicomaquea, 1107 a) en el sentido de que la virtud ha de entenderse como "término medio" sólo según su sustancia y su esencia; mientras que, según la perfección y el bien, ella constituye un "extremo". Hartmann habla, entonces, de una "dimensión axiológica" que, en la Etica Nicomaquea, se entrecruza con la dimensión ontológica, ${ }^{44}$ y que muestra el punto débil de la critica antiaristotélica que quiso ridiculizar la $\mu \varepsilon \sigma o ́ t \eta s$ comparándola con la "aurea mediocritas" (en lo cual se pasaba por alto el hecho de que Aristóteles, en el mencionado fragmento, había visto la virtud como un "extremo" axiológico). En el capítulo 61 Hartmann vuelve sobre la cuestión, vinculándola con la del esquema de oposiciones axiológicas: la relación entre el "defecto" y el "exceso" es un antagonismo de valores negativos (oposición del tipo 5.: desvalor-desvalor). Pero ocurre que, en la mayor parte de los casos, el lenguaje no posee suficientes palabras para designar a los valores positivos que se oponen a los negativos que aparecen en el "defecto" y el "exceso". Falta precisión en el lenguaje valorativo, y por eso es necesario expresar el carácter de muchos valores mediante rodeos aproximativos. Hartmann trata de probar que la $\mu \varepsilon \sigma o ́ t \eta 5$ aristotélica representa, en realidad, una "síntesis" de valores positivos. Lo importante es que ella puede considerarse "término medio" sólo en la dimensión ontológica; en la dimensión axiológica es un "extremo", y como tal se opone por igual al "defecto" y al "exceso": el tipo de oposición, en este caso, es el 3. (valor-desvalor). Si tomamos, por ejemplo, el caso de la "valentía", vemos que ésta aparece, según Aristóteles, como "término medio" entre "cobardia" (defecto) y "temeridad" (exceso); pero la valentía —al igual que las otras virtudes aristotélicas- representa un "momento axiológico" (Wertmoment) distinto si se la considera en su relación con el defecto o con el exceso: frente a la "cobardía", es algo así como una "perseverancia resuelta" (beherztes Ausharren), mientras que, frente a la "temeridad", se manifiesta más bien como una especie de "precaución prudente" (bedachtsame Vorsicht), o de "serena presencia

43 Cf. Ethik, Cap. 61.c, pp. $5^{6} 5$ ss.

44 Hartmann se basa explícitamente en un trabajo de Marie Luise von Kohoutek: Die

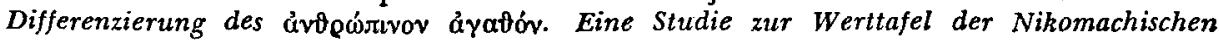
Ethik (Tesis doctoral inédita, Marburg, 1923). 
de ánimo" (kaltblütige Geistesgegenwart), que tiene, como aquella "perseverancia resuelta", signo axiológico positivo. La "valentía", entonces, más que un término medio entre "cobardía" y "temeridad", es la síntesis axiológica de esos dos difícilmente definibles valores positivos. Hartmann hace consideraciones semejantes con las demás virtudes aristotélicas, mostrando, en todos los casos, que éstas representan "síntesis axiológicas" en el sentido mencionado. 45

Aclara Hartmann, sin embargo, que hay una importante diferencia entre el cuadrado axiológico de oposiciones y este esquema de las virtudes aristotélicas. En aquél, la relación antinómica se da entre los valores positivos, sin necesidad de una correspondiente "antitética" entre los desvalores que se les oponen polarmente. En el caso de las virtudes aristotélicas, en cambio, la oposición evidente se da entre los valores negativos (defecto y exceso); mientras que, entre los positivos, la "síntesis" es posible porque no hay entre ellos oposición manifiesta. Precisamente los valores morales "superiores" (amor al prójimo, veracidad, fidelidad, etc.) no muestran carácter de "síntesis axiológicas". Pero ellos también se hallan frecuentemente en relaciones conflictuales: si no representan "síntesis" de otros valores, es porque ellos mismos pueden ser la contraparte positiva de valores negativos que se oponen. Es decir, estos "valores morales superiores" ocuparían, entonces, un lugar similar al de aquellos valores positivos casi indefinibles, de los cuales la "virtud" aristotélica representaba una "síntesis axiológica". Lo importante, en esta interpretación de la teoría de Aristóteles, es el hecho de que se pone el acento en la necesidad de la unificación entre distintas posibilidades de conducta. Ésta, en cuanto "moral" o "virtuosa", tiene entonces un valor más alto que el de los componentes axiológicos incluidos en ella. Y, precisamente, lo que se busca en cada caso de conflicto, es la posibilidad de una "síntesis axiológica". No se sabe, en principio, ante cuáles conflictos haya efectivamente esa posibilidad. Las auténticas "antinomias", como vimos, son insolubles, y no admiten, por tanto, la "síntesis". Pero la exigencia axiológica de una síntesis existe independientemente de su cumplimiento.46 Hay que tener en cuenta que las verdaderas "antinomias" son casos especiales dentro de las oposiciones axiológicas. Pueden haber, en cambio, en la situación concreta, conflictos entre todos los valores, que colocan al hombre constantemente ante la necesidad de decidir. Esto significa que, en principio, toda diferencia entre valores puede cobrar, en una determinada situación, carácter antinómico. La posibilidad de síntesis, entonces, no puede excluirse de antemano: su búsqueda es una exigencia moral que se mantiene para cada caso.47 El principio de la "síntesis axiológica" se convierte, por tanto, en una

45 Cf. Ethik, Cap. 61.e, pp. 568 ss.

46 Cf. Ethik, Cap. 61.f, p. 574 .

47 Cf. Ethik, Cap. 61.g, p. 576 . 
ley fundamental del reino de valores, aun cuando la síntesis correspondiente a cada oposición entre los "valores superiores", se mantenga -mientras no sea aprehendida por el "sentimiento axiológico"- como una mera hipótesis. Si esa hipótesis, en general, correspondiera a los hechos verdaderos, la ética se acercaría entonces a la idea de la "unidad de la virtud", elaborada por los antiguos estoicos, según la cual cada una de las virtudes presupone a todas las demás. ${ }^{48}$ Pero Hartmann no quiere, por lo pronto, ir tan lejos. Aquí, como en todas las partes de su filosofía, rechaza lo "constructivo", y en ello caería la pretensión de contar con un "principio dialéctico" que permitiera ir ascendiendo de unas sintesis en otras hasta alcanzar el bien absoluto: Toda construcción dialéctica "permanece como un juego ocioso mientras no se logre elevar también, con ella, la contemplación axiológica (Wertschau), y, en definitiva, el originario sentimiento del valor, hasta esa altura. Los valores tienen que ser sentidos, y sólo sobre la base de este sentir pueden ser contemplados. No hay otra manera de estar seguros de su ser-ensí ideal". ${ }^{49} \mathrm{El}$ sentimiento del valor progresa según sus propias leyes, y no puede ser acomodado por la fuerza a un esquema extraño, como se pretendería desde una actitud de impaciencia especulativa. Incluso las "síntesis axiológicas" sólo pueden hallarse en la medida en que el "sentimiento del valor" las alcance mediante su propio desarrollo.

Lo que hemos venido llamando "estructura antinómica" de la Ética de Hartmann se mantiene también en la Tercera Parte, es decir, en la Metafísica de las costumbres, donde está tratado el problema del "libre arbitrio". Aquí nos encontramos con las "antinomias de la libertad". La cuestión es abordada desde la perspectiva axiológica: el libre arbitrio del hombre es la "instancia" que, más allá del mero "sentimiento axiológico", decide la con. ducta frente a los valores. El hombre, cuando "siente" un determinado valor, puede "realizarlo" o no. En esto reside su libertad, a la cual se vinculan los valores morales. La expresión "libre arbitrio" no significa en Hartmann la mera libertad de la voluntad, sino que se extiende a la libertad de toda íntima "toma de posición."

A partir del planteamiento y la "solución" de la "antinomia" kantiana de la libertad (tecera antinomia de la Dialéctica Trascendental) se desarrollan las antinomias hartmannianas. Se trata, en primer lugar, de la "antinomia causal" (Kausalantinomie), en la que la libertad se enfrenta con la determinación causal. Es, justamente, la antinomia que "resolvio" Kant al establecer que la libertad moral no ha de entenderse en sentido negativo -como "libertad de algo"-, sino que representa algo positivo: una forma especial de determinación, ya no "causal". Lo "causal" alude aquí -para usar el Ienguaje aristotélico- a causas "eficientes", no a causas "finales". En un mun-

48 Cf. Ethik, Cap. 61. h, pp. 579 ss.

49 Ethik, Cap. 61. h, p. $5^{80}$. 
do determinado por causas "finales" no quedaría lugar para la libertad humana. Pero en un mundo determinado sólo por causas "eficientes" nada hace contradictoria la irrupción de un determinante positivo proveniente del mundo inteligible, de la "cosa en si" kantiana. La libertad humana, entonces, deja de concebirse como "indeterminación" o como un minus en determinación (concepto que la hacía incompatible con todo determinismo) y pasa a ser, por el contrario, un plus de determinación. En este sentido "positivo", constituye ahora una nueva legalidad, paralela a la legalidad natural: la legalidad teleológica. El hombre se propone fines y se empeña en su realización, introduciendo así en el mundo empírico una determinación distinta.

Pero, según Hartmann, con esto no se soluciona todo el complejo problema de la libertad. Sólo queda demostrada la "autonomía de la razón": la sujeción de ésta a su propia ley es, al mismo tiempo, libertad; es la "libertad trascendental", válida también para el "sujeto trascendental". Pero ésta no es, según Hartmann, la verdadera libertad moral, la que corresponde al individuo humano real. ${ }^{50}$ Hay que explicar cómo cada persona es libre frente a la ley moral: la "libertad frente al ser" no basta; tiene que haber también "libertad frente al deber ser". Este segundo aspecto - no resuelto y, por el contrario, complicado por Kant- es lo que Hartmann llama "antinomia del deber ser" (Sollensantinomie). Para ser realmente responsable, esto es, para tener carácter moral, la voluntad tiene que poder decidir también contra el "deber ser". En esta antinomia se oponen el "deber" (Sollen) y el "querer" (Wollen). Ese plus de determinación impuesto por la "razón práctica" contradice entonces a la libertad de la persona individual.

Hay aún una tercera "antinomia de la libertad", que Hartmann infiere del desarrollo de una serie de "aporias": ${ }^{51}$ consiste en la oposición entre los contenidos de las dos primeras, es decir, en la incompatibilidad de la solución de la "antinomia causal" con la de la "antinomia del deber ser". De ahí el carácter esencialmente "metafísico" del problema de la libertad: ese residuo, que escapa a la racionalidad, permanece insoluble.

Finalmente ve Hartmann otro grupo de "antinomias" entre la ética y la religión. Son fundamentalmente cinco: r) La "tendencia al más allá", propia de la religión, se opone a la "tendencia al más acá" propia de la ética. Son contradictorias, pues para la primera los valores de "este mundo" sólo tienen sentido en la relación con el "otro", mientras que para la segunda tal subordinación descalifica dichos valores. La inconsecuencia humana, sin embargo, hace que en toda persona se hallen ambas. No puede haber aquí solución racional. 2) Para la religión lo más importante es Dios;

50 Cf. Ethik, Cap. 72, b, pp. 687 ss.

51 La exposición de esas "aporías de la libertad moral" se halla en Ethik, Cap. 74. b, pp. $706 s$ s. 
para la ética, el hombre. La voluntad divina es necesariamente concebida como una instancia suprema; pero si a ella se le subordina la voluntad humana, pierde el hombre su autonomía y su responsabilidad. 3) El origen de los valores se halla, según la religión, en Dios, entendido como valor absoluto y condicionante de todos los demás. La ética, en cambio, sólo merece tal nombre cuando se fundamenta en la autonomía de los valores: la realización de éstos es "moral", no cuando se sigue de una orden o una obligación que viene de otra parte, sino cuando se lleva a cabo por sentírselos como valores en sí. 4) El clásico problema del antagonismo entre la Providencia y el libre arbitrio humano, para el cual tantas soluciones intentó la filosofía medieval, constituye en realidad una auténtica antinomia de la libertad, racionalmente insoluble. No se trata, propiamente, de una antinomia entre ética y religión, sino de un conflicto interno en el terreno de la religión, pues ésta necesita también de la libertad humana. Si no hay predeterminación divina, Dios pierde uno de sus atributos esenciales; pero, si la hay, el hombre no es libre, y por tanto no es responsable, y el concepto de "pecado" pierde su sentido. 5) La última antinomia es la de la "redención" o "salvación" (Erlösung), que constituye la contraparte de la anterior: Para la religión, el "pecado" puede ser "perdonado" y "borrado". Para la ética, por el contrario, la culpabilidad moral no puede ser anulada, pues ello degradaría al hombre en su carácter de ser responsable, lo desconocería como persona. ${ }^{\mathbf{2}}$

Es lícito, desde luego - y, efectivamente, se ha hecho con frecuenciadiscrepar con todas estas concepciones de la ética hartmanniana. Pero el elemento antinómico, que hemos tratado de destacar y que da a la obra su peculiar estructura, representa a nuestro juicio un aporte decisivo para toda ulterior investigación de los problemas éticos. No se puede prescindir de él sin amputar uno de los caracteres más sobresalientes del fenómeno moral: la conflictualidad. Tanto la ética de Hartmann como la de Scheler han sido el blanco predilecto de las más diversas direcciones de la crítica; y ello no puede considerarse carente de justificación. Sin embargo, quizá esa crítica haya pecado, más de una vez, en un defecto similar al de la adhesión incondicional y ortodoxa: la unilateralidad. En el caso particular de Hartmann, es preciso desarrollar aún una forma de enjuiciamiento que constituya, al mismo tiempo, una continuación de sus reflexiones y una corrección de sus fallas. Creemos que un primer paso en tal sentido sería la búsqueda de un acercamiento entre dos teorías de Hartmann que éste se ha empeñado en separar: sus concepciones de la experiencia de la realidad y de la "objetividad" de los valores. El carácter "ideal" de éstos es, nos parece, uno de los puntos débiles en esta filosofía, que, pese a la riqueza de sus análisis, requiere ser completada con un análisis ontológico (provisionalmente, el modelo podría estar en la propia "ontología crítica" hartmanniana) del fenó52 Estas "antinomias" están desarrolladas en el Cap. 85., último de la Ethik (pp. 808 ss.). 
meno de la valoración. Luego podrían atenderse también los diversos detalles de la ontología de lo real, núcleo del pensamiento de Hartmann. Pero ya aquel análisis a que nos referimos, permitiría, por lo pronto, y con respecto al problema específico que ahora hemos tratado, engranar la cuestión de la conflictualidad ontológica con la axiológica. A pesar del abismo artificial que Hartmann ha abierto entre ellas, no cabe duda que vio ambas con claridad y desde todas las perspectivas posibles. Con respecto a la Ethik, el tema de la conflictualidad, que da la pauta de toda una estructura antinómica de pensamieno, es el aspecto que debe tenerse especialmente en cuenta para todo estudio y todo comentario de este libro monumental.

\section{Universidad de La Plata}

Ricardo Maliandi 